\title{
Evaluation of the Levels of Renal Indices and Blood Pressure in Type 2 Diabetes Mellitus, Hypertensive and Normotensive Subjects in Port Harcourt, Nigeria
}

\author{
*11BARTIMAEUS, ES; KEN-EZIHUO, SU \\ ${ }^{1,2}$ Department of Medical Laboratory Science, Rivers State University of Science and Technology, \\ P.M.B. 5080, Nkpolu-Oroworukwo, Port Harcourt, Rivers State, Nigeria.

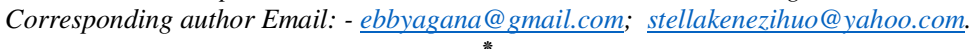

\begin{abstract}
This study was designed to find out the impact of diabetes mellitus on the renal integrity of diabetic patients following exposure to hypertension and diabetes. This was achieved by examining the urea and creatinine concentrations and creatinine clearance of both diabetics and non-diabetics in Port Harcourt. A total of 165 subjects comprising $32(19.39 \%)$ male diabetics, 53 (31.12\%) female diabetics, 48 (29.09\%) nondiabetic males and $32(19.39 \%)$ non-diabetic females participated in the study. Results showed that $9.09 \%$ of male and $21.91 \%$ of female diabetics were hypertensive. Mean urea concentrations obtained were $6.35 \pm 1.55$ $\mathrm{mmol} / \mathrm{L}$ and $5.56 \pm 2.24 \mathrm{mmol} / \mathrm{L}$ in the diabetic males and females respectively while in the non-diabetic males and females, the results were $5.66 \pm 1.23 \mathrm{mmol} / \mathrm{L}$ and $5.07 \pm 1.71 \mathrm{mmol} / \mathrm{L}$ respectively which was not significantly different $(\mathrm{p}>0.05, \mathrm{~F}$ crit. $=1.98)$. The creatinine concentration in the diabetic males and females were $93.46 \pm 24.97 \mu \mathrm{mol} / \mathrm{L}$ and $89.15 \pm 28.01 \mu \mathrm{mol} / \mathrm{L}$ respectively while in the non-diabetic male and female subjects it was $84.64 \pm 29.06 \mu \mathrm{mol} / \mathrm{L}$ and $81.69 \pm 37.27 \mu \mathrm{mol} / \mathrm{L}$ respectively. These means were not significant ( $p>0.05, \mathrm{~F}$ crit. $=1.65$ ). In both male and female diabetics, the creatinine clearance was reduced in the subjects following 8 years and above of exposure to diabetes mellitus, which is an indication of commencement of progressive loss of renal function in the diabetic patients. Thus, measurement of creatinine clearance should be included in the routine assessment of renal function especially in type 2 diabetes mellitus patients. @ JASEM
\end{abstract}

http://dx.doi.org/10.4314/jasem.v20i4.19

Keywords: Renal failure, diabetes mellitus, hyperglycaemia, hypoglycaemia, renal clearance.

Diabetes mellitus is a chronic disease that is spreading worldwide (International Diabetes Federation, 2010). According to the World Health Organization (WHO) at least 171 million people worldwide are at risk of diabetes mellitus (Wild et al. 2004). Its incidence is increasing rapidly, and it is estimated that by the year 2030, this number would double (International Diabetes Federation, 2006). Diabetes mellitus occurs throughout the world, but it is more common in the developed countries (The Improved Diabetes Atlas, 2006). The increase in the incidence of diabetes in developing countries follows the trend of urbanization and lifestyle changes but there is little understanding of the mechanisms (Rother, 2007). In a follow-up cross-sectional study of people living with diabetes in Rivers state (a core Niger Delta region), it was revealed that diabetes contributes substantially to the health problem; with type 2 diabetics presenting at diagnosis with the following complications, viz: neuropathy 439 (56.3\%), erectile dysfunction 283 (36.3\%), nephropathy $72(9.2 \%)$ and retinopathy $57(7.3 \%)$ (Chinenye and Young, 2011)

In a survey conducted in Port Harcourt metropolis, the prevalence of hypertension was found to be $40.82 \%$ out of which $13.03 \%$ were unaware of being hypertensive and $27.79 \%$ were already receiving treatment for hypertension Among those found to be hypertensive, $17.55 \%$ had family history of hypertension, and $12.23 \%$ had family history of diabetes mellitus (Akpa et al., 2008). However, in a review study of hypertension in Nigeria, the prevalence of hypertension in both men and women ranged from $8 \%$ to $46.4 \%$; with regards to gender, the prevalence of hypertension ranged from $7.9 \%$ to $50.2 \%$ and $3.5 \%$ to $6.8 .8 \%$ in men and women, respectively. The reported prevalence in rural areas ranged from $13.5 \%-46.4 \%$ in both sexes, $14.7 \%$ $49.5 \%$ in men and $14.3-68.8 \%$ in women. Data from urban studies revealed a range of $8.1 \%-42.0 \%$ in both men and women, $7.9 \%-46.3 \%$ for men and $3.5 \%$ $37.7 \%$ for women. In general hypertension prevalence was higher in urban than rural areas (Ogah et al., 2012).

Diabetes mellitus and hypertension has been found to co-exist in a number of patients. About 10 to $15 \%$ and 1 to $2 \%$ of Nigerians have hypertension and diabetes respectively (Akinkugbe, 2000). Data obtained from death certificates in the U.S.A. indicates that hypertension has been implicated in $44 \%$ of deaths coded to diabetes, and diabetes is involved in $10 \%$ of deaths to hypertension (Horan, 1984). The coexistence of these two diseases likely

*Corresponding author Email: - ebbyagana@gmail.com; stellakenezihuo@yahoo.com. 
contributes substantially to overall mortality in industrialized societies (Epstein and Sowers, 1992).

Elevated serum creatinine level $(80 \mu \mathrm{mol} / \mathrm{L}$ and 97 $\mu \mathrm{mol} / \mathrm{L}$ ) for elderly women and men respectively has been established with increased mortality in hypertensive persons with complications of type 2 diabetes mellitus and cardiovascular disease (Lynch and $\mathrm{Wu}, 2010)$. The literature relating levels of renal indices such as creatinine, urea, creatinine clearance in hypertensive and normotensive subjects and diabetes type 2 subjects is scarce in Nigeria. Realizing that diabetes mellitus and renal failure are major public health concerns, this study was designed to investigate the levels of these indices of renal function and blood pressure measurements in type 2 diabetic mellitus subjects in Port Harcourt, Nigeria.

\section{MATERIALS AND METHODS}

Subject selection: The study was carried out on subjects attending the out-patients' department of the Braithwaite Memorial Hospital, Port Harcourt, South- South Nigeria. The sample size was determined using the Taro Yamane's formula (Yamane, 1967) based on a prevalent hypertension population size of $45.4 \%$ as reported by Nwafor and Owhorji, (2001) in Port Harcourt. A total of one hundred and sixty- five (165) subjects participated in the study out of which sixty- four (64) were males and one hundred and one (101) were females. The subjects who participated in the study were within the age of 31 and 85 years.

Ethical Issues: Ethical approval and clearance was received from the Ethics Committee of the Rivers State Health Management Board and the Local Ethics Committee of the Braithwaite Memorial Hospital, Port Harcourt, Nigeria. The subjects voluntarily gave oral consent to participate in the study after the objectives of the study was explained to them.

Data collection: Information on history of hypertension and diabetes mellitus was obtained using a set of structured questionnaire. Diabetes mellitus was defined by participants' medical history and the diagnosis was based on the World Health Organization (WHO) criteria (Expert Committee on the Diagnosis and Classification of diabetes mellitus, 1997). Systolic blood pressure $>140 \mathrm{mmHg}$ and/or diastolic blood pressure $>90 \mathrm{mmHg}$ measured using standard procedures were used to make a diagnosis of hypertension (Guideline subcommittee, 1999). Blood pressure was obtained 3 times from each subject during the survey. Each measurement was made using a mercury sphygmomanometer, with the participant seated. The arithmetic mean was then calculated using all available systolic and diastolic readings. In this analysis, individuals with a systolic blood pressure lower than $140 \mathrm{~mm} \mathrm{Hg}$ and diastolic blood pressure lower than $90 \mathrm{~mm} \mathrm{Hg}$ who were not receiving antihypertensive treatment were defined as normotensive. Individuals were classified as hypertensive if they had a mean blood pressure of $140 \mathrm{mmHg}$ or higher (systolic) or $90 \mathrm{mmHg}$ or higher (diastolic) or reported current use of medication for hypertension (Burt et al., 1995). The height was measured (in metres) to the nearest $0.1 \mathrm{~m}$ with a calibrated meter rule placed horizontally against the wall while the weight of the subjects was measured (in kilograms) with participants wearing light clothing and no shoes, and recorded to the nearest $0.1 \mathrm{~kg}$ as recommended by the World Health Organization (WHO, 1995).

Determination of Serum Creatinine: Serum creatinine level was determined by the alkaline Jaffe's Picrate (Owen et al.,1954). The Jaffe's method for serum creatinine determination is based on the principle that picric acid in an alkaline medium reacts with creatinine to form an orange coloured complex with the alkaline picrate. The absorbance of the complex formed whose intensity is directly proportional to the amount of creatinine present in the sample is read in a spectrophotomer at $490 \mathrm{~nm}$.

Determination of Serum urea: The serum urea level was determined by the diacetyl monoxime method as reported by Cheesbrough, (2005). In the diacetyl monoxime method, urea reacts with diacetyl monoxime at high temperature in an acid medium in the presence of cadmium ions and thiosemicarbazide to produce a red coloured solution whose absorbance is read at $530 \mathrm{~nm}$ in spectrophotomer.

Determination of Plasma Glycated Haemoglobin Alc: Diabetes mellitus in the subjects was confirmed by the determination of plasma glycated haemoglobin A1c by the method of Bisse and Abraham (1985). The method involves chromatographicspectrophotometric ion exchange procedures for the determination of haemoglobin A1c. The glycohaemoglobin procedure employs a weakly binding cation-exchange resin for rapid separation of glycohaemoglobin (fast fraction) from nonglycosylated haemoglobin. The percent glycohaemoglobin is determined by measuring absorbance at $415 \mathrm{~nm}$ for the glycohaemoglobin fraction and the total haemoglobin fraction, calculating the ratio of the absorbance. An HbA1c of $6.5 \%$ as recommended by WHO (2011) was adopted as the cut point for diagnosing diabetes and subjects 
with $\mathrm{HbA1c}$ values below $6.5 \%$ were regarded as non- diabetic.

Determination of Creatinine Clearance (Calculated): The creatinine clearance which is practically the same as the glomerular filtration rate was estimated using Cockcroft-Gault formula (Cocroft and Gault, 1976). The formula takes into account various factors that affects the estimation of muscle mass and assumed creatinine production since serum creatinine is so highly dependent on age, sex and body size. It is given as:

Creatinine clearance $(\mu \mathrm{mol} / \mathrm{L})=(((140-$ age $) \mathrm{x}$ weight $) /(0.814 \mathrm{x}$ serum [creatinine] $) \times(0.85$ if patient is female)), where creatinine clearance is in millilitres per minute, age is in years, weight is kilograms, [creatinine] in micromoles per litre.

Statistical analysis: GraphPad Instat Version 3.10, 12 bit for windows was used for the statistical evaluation of the results obtained. All data are presented as means \pm SD since variables presented were normally distributed. One-way analysis of variance (ANOVA) was also used as appropriate to compare means of variables. Variation in means was considered significant at $\mathrm{p}<0.05$.

\section{RESULTS AND DISCUSSION}

There were one hundred and sixty-five subjects comprising 32 subjects (19.39\%) who were male diabetics, 53 subjects (32.12\%) who were female diabetics, 48 subjects (29.09\%) who were nondiabetic males, and 32 subjects (19.39\%) who were non-diabetic females. Amongst the diabetics, 15 male subjects $(9.09 \%)$ and 36 female subjects (21.81\%) were hypertensive whilst 15 male subjects (9.09\%) and 18 female subjects (10.91\%) were normotensive. The mean \pm SD of the systolic blood pressure (SBP) obtained from the diabetic male and female subjects were $142.55 \pm 10.48 \mathrm{mmHg}$ and $149.88 \pm 21.67 \mathrm{mmHg}$ while the diastolic blood pressure (DBP) were $90.77 \pm 11.75 \mathrm{mmHg}$ and 90.70 $\pm \mathrm{mmHg}$ respectively. Also, the mean $\pm \mathrm{SD}$ of the systolic blood (SBP) pressure obtained from the nondiabetic male and female subjects were $129.82 \pm 6.87$ $\mathrm{mmHg}$ and $82.85 \pm 7.06 \mathrm{mmHg}$ while the diastolic blood pressure (DBP) were $79.59 \pm 11.75 \mathrm{mmHg}$ and $90.70 \pm \mathrm{mmHg}$ respectively. Comparison of the means of the systolic blood pressure between the diabetic male, diabetic female, non-diabetic male and non-diabetic female subjects using analysis of variance (ANOVA) showed significant difference $(\mathrm{p}<0.05$, F-crit. $=24.83)$. Similarly, the comparison of the means of the diastolic blood pressure between the diabetic male, diabetic female, non-diabetic male and non-diabetic female subjects using analysis of variance (ANOVA) also showed significant difference $(\mathrm{p}<0.05$, F-crit. $=18.83)$.

Furthermore, the mean \pm SD of the serum urea concentration of the diabetic male and female subjects were $6.36 \pm 1.55 \mathrm{mmol} / \mathrm{L}$ (4.81$7.91 \mathrm{mmol} / \mathrm{L})$ and $5.56 \pm 2.24 \mathrm{mmol} / \mathrm{L}(3.32-7.80$ $\mathrm{mmol} / \mathrm{L}$ ) respectively. The mean $\pm \mathrm{SD}$ of the serum urea concentration of the non-diabetic male and female subjects were $5.66 \pm 1.23 \mathrm{mmol} / \mathrm{L}(4.43-6.89$ $\mathrm{mmol} / \mathrm{L})$ and $5.07 \pm 1.71 \mathrm{mmol} / \mathrm{L} \quad(3.36-6.78$ $\mathrm{mmol} / \mathrm{L}$ ) respectively. The mean of serum urea concentrations in the male and female diabetic and non-diabetic subjects were not significantly different (p>0.05, F-crit.=1.98) when compared using ANOVA. The urea reference range used to compare with data obtained in this study was $2.5-8.0 \mathrm{mmol} / \mathrm{L}$ according to Tietz et al. (1995).

The mean \pm SD of the serum creatinine concentration in the diabetic male and female subjects were $93.46 \pm$ $24.97 \mu \mathrm{mol} / \mathrm{L}(68.49-118.43 \mu \mathrm{mol} / \mathrm{L})$ and $89.15 \pm$ $28.01 \mu \mathrm{mol} / \mathrm{L}(61.14-117.17 \mu \mathrm{mol} / \mathrm{L})$ respectively while the serum creatinine concentration in the nondiabetic male subjects was $84.64 \pm 29.06 \mu \mathrm{mol} / \mathrm{L}$ $(55.58-113.7 \mu \mathrm{mol} / \mathrm{L})$ and the mean $\pm \mathrm{SD}$ of serum creatinine concentration for the non-diabetic female subjects was $81.69 \pm 37.27 \mu \mathrm{mol} / \mathrm{L}(44.42-118.96$ $\mu \mathrm{mol} / \mathrm{L})$. The comparison of the means of serum creatinine concentration from all the subjects did not show significant difference $(p>0.05$, F-crit. $=1.65)$. The male creatinine reference range used to compare with the data obtained in this study was 70-120 $\mu \mathrm{mol} / \mathrm{L}$ while the female creatinine reference range was $50-90 \mu \mathrm{mol} / \mathrm{L}$ according to Tietz et al. (1995).

The mean \pm SD of the estimated creatinine clearance for the diabetic male and female subjects were 91.61 $\pm 45.44 \mathrm{ml} / \mathrm{min} / 1.73 \mathrm{~m}^{2}\left(46.17-137 \mathrm{ml} / \mathrm{min} / 1.73 \mathrm{~m}^{2}\right)$ and $85.15 \pm 33.50 \mathrm{ml} / \mathrm{min} / 1.73 \mathrm{~m}^{2}$ (51.65-118.65 $\mathrm{ml} / \mathrm{min} / 1.73 \mathrm{~m}^{2}$ ). The creatinine clearance values for the male and female diabetics showed lower values at the lower range of normal. The creatinine clearance value for the non-diabetic male and female subjects were $99.06 \pm 26.34 \mathrm{ml} / \mathrm{min} / 1.73 \mathrm{~m}^{2}(72.72-125.4$ $\mathrm{ml} / \mathrm{min} / 1.73 \mathrm{~m}^{2}$ ) and $90.09 \pm 35.28 \mathrm{ml} / \mathrm{min} / 1.73 \mathrm{~m}^{2}$ $\left(54.81-125.37 \mathrm{ml} / \mathrm{min} / 1.73 \mathrm{~m}^{2}\right)$ respectively. A nonsignificant difference $(\mathrm{p}>0.05$, F-crit. $=1.32)$ was observed between these means. This is shown in table 1. The means of the creatinine clearance for the nondiabetic male and female subjects were generally within the normal limits reported by Tietz et al. (1995). 
The mean \pm SD of the creatinine clearance classified according to the number of years of exposure to or duration of type 2 diabetes mellitus in the subjects was determined and results shown in the table 2. The table showed that the mean \pm SD of the creatinine clearance in the diabetic male $(14.12 \%)$ and female (30.59\%) subjects whose duration of exposure to diabetes was between $0-3$ years was $72.67 \pm 40.54$ $\mathrm{ml} / \mathrm{min} / 1.73 \mathrm{~m}^{2}\left(32.12-113.21 \mathrm{ml} / \mathrm{min} / 1.73 \mathrm{~m}^{2}\right)$ and $82.70 \pm 34.12 \mathrm{ml} / \mathrm{min} / 1.73 \mathrm{~m}^{2} \quad(48.54-116.82$ $\mathrm{ml} / \mathrm{min} / 1.73 \mathrm{~m}^{2}$ ) respectively. In those subjects whose duration of exposure to diabetes was between 4-7 years, the creatinine clearance was $96.63 \pm 24.75$ $\mathrm{ml} / \mathrm{min} / 1.73 \mathrm{~m}^{2}\left(61.91-121.35 \mathrm{ml} / \mathrm{min} / 1.73 \mathrm{~m}^{2}\right)$ in the male and $81.81 \pm 39.63 \mathrm{ml} / \mathrm{min} / 1.73 \mathrm{~m}^{2}$ (42.18$121.44 \mathrm{ml} / \mathrm{min} / 1.73 \mathrm{~m}^{2}$ ) in the female subjects respectively. The creatinine clearance for the male diabetics $(8.24 \%)$ whose duration of exposure to diabetics was from 8 years and above was $57.24 \pm$ $12.82 \mathrm{ml} / \mathrm{min} / 1.73 \quad\left(44.42-70.06 \mathrm{ml} / \mathrm{min} / 1.73 \mathrm{~m}^{2}\right)$ while the creatinine clearance for the female diabetics whose duration of exposure to diabetes was from 8 years and above (22.35\%) was $83.04 \pm 33.67$ $\mathrm{ml} / \mathrm{min} / 1.73 \mathrm{~m}^{2}$ (49.37- $\left.116.67 \mathrm{ml} / \mathrm{min} / 1.73 \mathrm{~m}^{2}\right)$. The reference range of creatinine clearance is $95-140$ $\mathrm{ml} / \mathrm{min} / 1.73 \mathrm{~m}^{2}$ for males and $85-125 \mathrm{ml} / \mathrm{min} / 1.73 \mathrm{~m}^{2}$ for females according to Tietz et al. (1995). These results showed reduced creatinine clearance in the lower range of normal for both male and female diabetics. Comparison of the means of the creatinine clearance according to the duration of exposure to diabetes mellitus using ANOVA amongst the male diabetics showed significant difference $(\mathrm{p}<0.05$, Fcrit. $=16.56)$ in the males while in the females no significant difference $(\mathrm{p}>0.05$, F-crit. $=1.23)$ was observed. The range of the creatinine clearance value was low at the lower limits of normal when compared with the reference range in both the male and female diabetics.

Table 1: Blood Pressure Measurements and Some Renal Indices in the Subjects

\begin{tabular}{|c|c|c|c|c|c|c|}
\hline Subjects & Number $(\%)^{*}$ & $\overline{\mathrm{SBP}}(\mathrm{mmHg})$ & $\begin{array}{c}\mathrm{DBP} \\
(\mathrm{mmHg})\end{array}$ & $\begin{array}{c}\text { Serum Urea } \\
(\mathrm{mmol} / \mathrm{L})\end{array}$ & $\begin{array}{c}\text { Serum Creatinine } \\
(\mu \mathrm{mol} / \mathrm{L})\end{array}$ & $\begin{array}{l}\text { Creatinine Clearance } \\
(\mathrm{ml} / \mathrm{min} / 73.2)\end{array}$ \\
\hline Diabetic Males & $32(19.39)$ & $142.55 \pm 10.48$ & $\begin{array}{l}90.77 \pm \\
11.85\end{array}$ & $6.36 \pm 1.55$ & $93.46 \pm 24.97$ & $91.61 \pm 45.44$ \\
\hline Non-Diabetic Males & $32(19.39)$ & $129.82 \pm 8.23$ & $79.59 \pm 6.87$ & $5.66 \pm 1.23$ & $84.64 \pm 29.06$ & $99.06 \pm 26.34$ \\
\hline Diabetic Females & $53(32.12)$ & $149.88 \pm 21.67$ & $\begin{array}{l}90.70 \pm \\
11.75\end{array}$ & $5.56 \pm 2.24$ & $89.15 \pm 28.01$ & $85.15 \pm 33.50$ \\
\hline $\begin{array}{l}\text { Non-Diabetic } \\
\text { Females }\end{array}$ & 48 (29.09) & $127.70 \pm 9.22$ & $82.85 \pm 7.06$ & $5.07 \pm 1.71$ & $81.69 \pm 37.26$ & $90.09 \pm 35.28$ \\
\hline P-value & & $\mathrm{p}<0.05, \mathrm{~F}=24.83$ & $\begin{array}{l}\mathrm{p}<0.05, \\
\mathrm{~F}=18.32\end{array}$ & $\mathrm{p}>0.05, \mathrm{~F}=1.98$ & $\mathrm{p}>0.05, \mathrm{~F}=1.65$ & $\begin{array}{l}\mathrm{p}>0.05, \\
\mathrm{~F}=1.32\end{array}$ \\
\hline
\end{tabular}

Note: $*$ Number in parenthesis represents percentages

$\mathrm{SBP}=$ Systolic blood pressure

$\mathrm{DBP}=$ Diastolic blood pressure

Table 2 Table 2: Effect Duration of Diabetes Mellitus on Creatinine Clearance of Subjects

\begin{tabular}{|c|c|c|c|c|}
\hline $\begin{array}{c}\text { Duration of Diabetes } \\
\text { (years) }\end{array}$ & $\begin{array}{c}\text { Number of Subjects } \\
(\%)^{*} \text { Males }\end{array}$ & $\begin{array}{l}\text { Creatinine Clearance } \\
\left(\mathrm{ml} / \mathrm{min} / 1.73 \mathrm{~m}^{2}\right.\end{array}$ & $\begin{array}{c}\text { Number of Subjects } \\
(\%) \\
\text { Females } \\
\end{array}$ & $\begin{array}{c}\text { Creatinine } \\
\text { Clearance }\left(\mathrm{ml} / \mathrm{min} / 1.73 \mathrm{~m}^{2}\right)\end{array}$ \\
\hline $0-3$ & $12(14.12)$ & $72.67 \pm 40.54$ & $26(30.59)$ & $82.70 \pm 34.12$ \\
\hline $4-7$ & $13(15.29)$ & $96.63 \pm 24.75$ & $8(9.41)$ & $81.81 \pm 39.63$ \\
\hline 8 and above & $7(8.24)$ & $57.24 \pm 12.82$ & $19(22.35)$ & $83.04 \pm 33.67$ \\
\hline
\end{tabular}

Note: *Number in parenthesis represents percentages 
Diabetes mellitus (DM) is a chronic disorder that is not only assuming pandemic proportions worldwide but also poised to affect the developing countries of the world much more than their developed counterparts. Health care delivery as in most developing countries of the world is at best sub-optimal and this may be responsible for the dismal health indicator statistics such as reduced life expectancy at birth and increased maternal mortality. In this study, hypertension was defined as systolic blood pressure (SBP) $\geq 140$ and/ or diastolic blood pressure $\geq 90 \mathrm{mmHg}$. In a study on the prevalence of hypertension amongst persons with diabetes mellitus in Benin City, Nigeria, the proportion of male diabetics with hypertension was shown to be $50.8 \%$ and while that of the females was $49.2 \%$. The prevalence of hypertension in type 2 diabetes mellitus subjects was also observed to be $58.9 \%$ combined for both males and females (Unadike et al., 2011). The incidence of hypertension has been reported to be almost twice in diabetics as in non-diabetics (Epstein and Showers, 1992; Williams and Pickup, 1999). Analysis from our data showed that $51.51 \%$ (19.39\% and $32.12 \%$ of the diabetic male and female patients) were hypertensive which did not support earlier findings (Epstein and Showers, 1992; Williams and Pickup, 1999). Variable rates of hypertension in type 2 diabetes mellitus subjects have also been reported, viz, 30\% (Okesina et al., 1995), 37\% (Kumwenda et al.,1992) and 45\% (Swai et al., 1990) respectively. Our finding indicates a rising trend in the prevalence of hypertension in patients with type 2 diabetes mellitus which may be attributable to changes in life style due to modernization and rural urban migration which is sweeping across Nigeria. The high prevalence rate of hypertension in type 2 diabetes mellitus patients in this study may also be due to much stress as a result of the harsh economic conditions prevalent in this region of Nigeria coupled with the high level of insecurity and fear arising from rampant kidnappings and militancy operations.

In diabetic individuals, hypertension has been implicated in the accelerated progression of both microvascular and macrovascular complications (Williams, 1994). Diabetic nephropathy has also been reported to occur in approximately $1 / 3^{\text {rd }}$ of individuals with type 1 and type 2 diabetes mellitus. (Rehman et al., 2005). Diabetic nephropathy which could lead to reduction in creatinine clearance, which is a function of glomerular filtration rate, was evidently observed in this study. Our study shows that $30.59 \%$ (8.24\% males and $22.35 \%$ females) with an average age of duration of diabetes of 8 years and above showed creatinine clearance below the lower limits of normal, an observation that agrees with the findings of Williams (1994).
Diabetes mellitus is one of the major causes of renal morbidity and mortality and diabetic nephropathy is a prominent feature in chronic renal failure (Ortega et al.2005). Diabetic nephropathy is one of the kidney diseases that occur as a result of diabetes mellitus. Measurement of the serum urea and creatinine is widely used to assess renal integrity and function. An increase in urea level is seen when there is damage to the kidney or when the kidney is not functioning properly. It has been reported that increment in blood urea level in confirmed diabetics results from renal damage caused by increased blood sugar in the diabetics (Shrestha et al., 2008). It has also been reported that increase serum urea and creatinine in diabetic rats indicates progressive renal damage (Anjaneyulu et al., 2004). Plasma urea and creatinine are established markers of glomerular filtration rate (GFR) though plasma creatinine is a more sensitive index of kidney function compared to plasma urea because it fulfills most of the requirements for a perfect filtration marker (Perrone et al., 1992). Our finding suggests salient progressive degeneration of the kidney function and integrity in the diabetic females as revealed by the values of the serum creatinine measured. Remarkable increase in the upper limit of the range of the serum creatinine level was also observed in the female diabetics $(61.14-117.17 \mu \mathrm{mol} / \mathrm{L})$. Secondly, commencement of progressive loss of renal function in the diabetic patients in this study could be predicted by the findings of decrease in the lower limit of the creatinine clearance values in both the male and female type 2 diabetes mellitus patients. The range of the estimated creatinine clearance for the diabetic male and female subjects were $46.17-137 \mathrm{ml} / \mathrm{min} / 1.73 \mathrm{~m}^{2}$ and $51.65-118.65 \mathrm{ml} / \mathrm{min} / 1.73 \mathrm{~m}^{2}$ respectively These findings further strengthened the assertion by Perrone et al. (1992) that plasma creatinine is a more sensitive index of kidney function when compared with plasma urea.

The impact of average years of diabetes (duration of exposure to diabetes mellitus) cannot be overemphasized. Walaa (2005), has reported that after many years of diabetes, the delicate filtering system in the kidney becomes destroyed, initially becoming leaky to larger blood proteins such as albumin which are then lost in the urine. At this stage, the glomerular filtration rate begins to reduce tremendously. The present study shows that the average age of duration of diabetes mellitus with decrease in creatinine clearance is 8 years and above in both the male and female diabetics. This observation is lower than that obtained by Rehman and Hamayun (2004) who reported a duration of diabetes in insulin dependent diabetes mellitus (IDDM) nephropathy of $13.19 \pm 0.22$ years. However, only non- insulin dependent diabetic mellitus patients were considered in this study. The reasons for this 
observation may range from poor diabetic control, complications and effect of hypertension in the diabetic process, poor dietary habits as a result of the socioeconomic status of the subjects and the fact that most of the subjects might have had undiagnosed diabetes for a period longer than when diabetes was actually diagnosed in them.

Conclusion: This study showed that $51.51 \%$ (19.39\% males and $32.12 \%$ females) of the diabetic patients were hypertensive and that $30.59 \%$ ( $8.24 \%$ males and $22.35 \%$ females) with an average age of duration of diabetes 8 years and above show creatinine clearance below the lower limits of normal, an observation which is an indication of commencement of progressive loss of renal function in the diabetic patients who participated in the study. In order to monitor the impact of type 2 diabetes mellitus and hypertension on the integrity of the kidney in diabetics, there is a need to include the measurement of creatinine clearance among the routine biochemical tests used in the assessment of renal function especially in type 2 diabetes mellitus patients. The use of Cockroft-Gault equation in the estimation of creatinine clearance which clearly overcomes the drawbacks often associated with creatinine clearance measurement involving collection of urine specimens from patients is recommended. This is critical in the care of the diabetic patients since poorly managed diabetes mellitus could result in the development cardiovascular disease, a condition that is often complicated and even compromised when hypertension has developed in the diabetes mellitus patients.

Competing interests: The author(s) declare that they have no competing interests.

Acknowledgements: The staff of the Department of Medical Laboratory Services, Braithwaite Special Memorial Hospital, Port Harcourt for their assistance during sample collection, staff of the Chemical Pathology Laboratory, Department of Medical Laboratory Science, Rivers State University of Science and Technology, Port Harcourt for their assistance during laboratory analysis and my personal assistants for the secretarial assistance and logistics support.

\section{REFERENCES}

Akinkugbe, O O (2000). Non-communicable diseases in Nigeria. The next epidemics; Abayomi Memorial Lectures. Nig. J. Med. Pract. 3: 904-907.

Akpa, M R; Emem-Chioma, P C; Odia, O J (2008). Current epidemiology of hypertension in Port Harcourt metropolis, Rivers State, Nigeria. P. $H$. Med. J 2(3): 218-223.
Anjaneyulu, M; Chopra, K 2004). Quercetin: an antioxidant bioflavonoid attenuates diabetic nephropathy in rats. Clin. Exper. Pharm. Physio.31: 244-248.

Bisse, E; Abraham, E C (1985). New less temperaturesensitive micro-chromatographic method for the separation and quantitation of glycosylated haemoglobin using a non-cyanide buffer system. $J$. Chromat. 344: 81-91.

Burt, V L; Whelton, P; Roccella, E J (1995). Prevalence of hypertension in the US adult population. Hypertens. 25: 305- 313

Cheesbrough, M. (2005). Clinial chemistry tests. In: District Laboratory Practice in Tropical Countries Part 1 (2edn.). Sheck Wah Tong Printing Press Ltd, Hong Kong, p310.

Chinenye, S; Young, E (2011). State of diabetes care in Nigeria: a review. The Niger. Healt. J. 1(4): 101106.

Cockroft, D W; Gault, M H (1976). Prediction of creatinine clearance from serum creatinine. Nephron. 1631-1635

Epstein, M; Sowers, J R (1992). Diabetes mellitus and hypertension. Hypertens. 19: 403-418.

Expert Committee on the Diagnosis and Classification of Diabetes Mellitus, Report of the Expert Committee on the Diagnosis and Classification of Diabetes Mellitus (1997). Diab. Care: 20:11831197.

Guidelines Subcommittee, World Health OrganizationInternational Society of Hypertension Guidelines for the Management of Hypertension (1999). J Hypertens.: 17:151- 183

Horan, M J (1984). Diabetes and hypertension in National Diabetes Data Group: Diabetes in America: Diabetes Data Compiled 1984. US Department of Health and Human Services, publication No (NIH) 85-1468,1985, Chap XVII,XVII-I-XVII-21.

International Diabetes Federation.(2006). The IDF consensus worldwide definition of the metabolic syndrome. IDF Communications, Brussels.

International Diabetes Foundation. (2010). IDF Member Association Consultation on Diabetes on Diabetes Priorities for the UN Summit on NCDs. Brussels, Belgium. 
Kumwenda, J; Harries, A D; Nyrenda, C; Wirima, J J (1992). Diabetes mellitus and hypertension in Malawi adults. Mal. Ann. Med. J. 8: 129-231

Lynch, K L; Wu, A H B (2010). Renal functio In nBishop, M.L., Fody, E.P and Schoeff, L.E., (eds.) Clinical Chemistry: Techniques, Principles, Correlations, $6^{\text {th }}$ edn, Lippincott Williams \& Wilkins, Philadelphia p557.

Nwafor, A; Owhorji, A (2001). Prevalence of diabetes mellitus among Nigerians in Port Harcourt. J. Appl. Sci. Environ. Manage 5(1): 75-77.

Ogah, O S; Okpechi, I; Chukwuonye, I I; Akinyemi, J $\mathrm{O}$; Onwubere, B J C; Falase, A O; Stewart S; Sliwa, K (2012). Blood pressure, prevalence of hypertension and hypertension related complications in Nigerian Africans: a review. W. $J$. Cardio. 4: 327-340.

Okesina, A B; Omotoso, A B; Gadzama, A A; Ogunrinola, E O (1995). Frequency of hypertension in diabetic patients: Relationship with metabolic control, body mass index, age and sex. Intern. Diab. Dig. 7: 39-40

Ortega, O; Rodriguez, I; Molina, A; Hernandez, A (2005). Chronic renal failure - complications, cardiovascular morbidity/mortality, 73-74.

Osuntokun, B O (1972). Hypertension in Nigerian diabetics: a study of 832 patients. Afri. J. Med. Sci. 3: $257-265$

Owen, A; Iggo, B; Scandrett, F J; Stewart, C P (1954). The determination of creatinine in plasma or serum and in urine. A critical examination. Biochem. $J$. 58: 426 .

Perrone, R D; Madias, N E; Levey, A S (1992). Serum creatinine as index of renal function. Clin. Chem.38:1933-1953.

Rehman, G. and Hamayun, M (2004). Studies on diabetic nephropathy and secondary disease in type 1 diabetes. Int. J. Diab. Dev. Countries. 24: 50-55.

Rehman, G; Kan, S. A; Hamayun, M (2005). Studies on diabetic nephropathy and secondary diseases in type 2 diabetes. Int. J. Diab. Dev. Countries. 25: 25-29

Rother, K I (2007). Diabetes treatment- bridging the divide. N. Engl. J. Med. 356(15): 14991501.Shrestha, S; Gyawali, P; Shrestha, R; Poudel, B; Sigdel, M; Regmi, P; Shrestha, M; Yadav, B K
(2008). Serum urea and creatinine in diabetic and non- diabetic subjects. J Nepal Assoc. Med. Lab. Sci. 9(1): 11-12.

Sola, A O; Chinyere, O I; Stephen, A O; Kayode, J A (2013). Hypertension prevalence in an urban and rural area of Nigeria. J. Med. Med. Sci. 4(4): 149154.

Swai, A B; Lutale, J; McLarty, D G (1990). Diabetes in tropical Africa: a prospective study 1981-7. Characteristics of newly presenting diabetics in Dar es Salaam, Tanzania. Brit. Med. J. 300:11031106.

The Improved Diabetes Atlas (2006). $3^{\text {rd }}$ ed. International Diabetes Federation

Tietz, N W; Pruden, E L; Mcpherson, R A; Fuhrman, S A (1995). Clinical Guide to Laboratory Tests. $3^{\text {rd }}$ edn. W.B.Saunders Company, Philadelphia, USA, p1.

Unadike, B C; Eregie, A; Ohwovoriole, A E (2011). Prevalence of hypertension amongst persons with diabetes mellitus in Benin City, Nigeria. Niger. J. Clin. Pract. 14 (3): 300-302.

Walaa, S (2006). Diabetic nephropathy. Edren Juny, 25.

Wild, S; Roglic, G; Green, A; Sicree, R; King, H (2004). Global prevalence of diabetes: estimates for the year 2000 and projections for 2030. Diab. Care 27: 1047-1053

Williams, B (1994). Insulin resistance: The shape of things to come. Lancet 344: 521-524.

Williams G., Pickup J (1999). Handbook of Diabetes. Second edition. London, Blackwell Science.

World Health Organization (1995). Technical Report Series-854. Physical Status: The use and interpretation of anthropometry. WHO, Geneva

World Health Organization (2011). Use of glycated haemoglobin $\mathrm{A} 1$ in the diagnosis of diabetes mellitus. Geneva, WHO Press, pp. 1-25.

Yamane, T (1967). Statistics: An Introductory Analysis, 2nd Ed., New York: Harper and Row. 